\title{
Propuesta de entrenamiento psicológico integrado al deportivo en dos jugadoras de tenis de mesa: una experiencia en el CAR Sant Cugat de Barcelona
}

\section{Proposal of psychological training integrated into sport training in two table tennis players table-tennis: an experience in the CAR Sant Cugat of Barcelona}

Fecha de recepción: 03/10/2016

Fecha de aceptación: 13/10/2016
Lucía Abenza Cano

UCAM

Aurelio Olmedilla Zafra

Universidad de Murcia

Constanza Martínez

\section{resumen/alostract:}

El presente trabajo aborda el entrenamiento psicológico integrado al deportivo con deportistas desde una perspectiva interdisciplinar. Concretamente, el dirigido a dos jugadoras juveniles de tenis de mesa del equipo nacional español, internas en el Centro de Alto Rendimiento de Sant Cugat de Barcelona. Se describe el sistema de evaluación psicológica, el programa de intervención y se discuten los resultados derivados de la implementación del entrenamiento psicológico integrado al deportivo. En el programa de intervención se ofrece una descripción general de la planificación anual, en la cual se integran las estrategias psicológicas en función del momento de la temporada y de la relevancia de las competiciones. La intervención psicológica desarrollada con las tenimesistas evidencia una mejora en el dominio de las habilidades psicológicas relacionadas con la optimización del rendimiento deportivo.

This paper approaches psychological training integrated into sport training for athletes from an interdisciplinary perspective. Specifically, it focuses on two young players of table-tennis within the Spanish national team, who are enrolled in the High Performance Center of Sant Cugat of Barcelona. This intervention program describes the system of psychological assessment, and both such program and the corresponding results are discussed and derived from psychological training which is incorporated into traditional sport training. A general description of the annual planning is shown in the program of intervention. Such planning involves the psychological workload according to the different stages of the season and the importance of competitions. The psychological intervention developed with the tenimesists evidences an improvement in the mastery of the psychological abilities related to the optimization of the sport performance.

\section{palabras clave/keywords:}

Psicología; Entrenamiento integrado; Tenis de mesa; Alto rendimiento.

Psychology, Integrated training, table-tennis, elite sport. 


\section{Introducción}

El tenis de mesa es presentado principalmente como un deporte individual, (pese a que los entrenamientos sean obligatoriamente en grupo y en la competición se juegue dobles y equipos) de oposición y sin características cíclicas (López, 2009). Esto quiere decir, que se dan continuamente periodos de descanso y de juego, en los que la psicología juega un papel de vital importancia, tratando de recuperar y fortalecer la mente del jugador en los descansos, y hacer que, durante el juego, el estado psicológico del mismo no interfiera en el análisis y la consecuente solución motriz de manera negativa. Durante el juego, el punto clave lo marca la toma de decisiones tácticas: dónde enviar la bola (dependiendo de la posición del rival) y cómo hacerlo (con o sin efecto, cortado, lateral, entre muchos otros). Por ello, esta disciplina deportiva muestra una gran dificultad perceptiva y decisional (López, 2009; Mingchang, 2014). Durante la competición, el jugador depende completamente de su capacidad para luchar contra su rival en una situación altamente impredecible y dinámica. Poseer recursos de afrontamiento es un requisito previo para que el tenimesista juegue plenamente su táctica, y mantenga un funcionamiento armónico a pesar de los elementos potencialmente estresantes inherentes a la confrontación. Sin no maneja dichos recursos de afrontamiento, es muy difícil que el jugador salga victorioso de una situación crítica durante el partido (Duan, 2014; Godoy-Izquierdo, Vélez y Pradas, 2007; López, 2009; Mingchang, 2014; Séve, Ria, Poizat, Saury y Durand, 2007; Urra, 2014).

El resultado del análisis en los últimos años de las características psicológicas de destacados jugadores chinos (referentes internacionales) revela que atributos como el autocontrol, la flexibilidad, la racionalidad, la motivación hacia el logro, la perseverancia y la vitalidad son propios de estos excelentes deportistas (Mingchang, 2014).

Mora, Zarco y Blanca (2001) definen el entrenamiento psicológico como aquel que busca beneficiar, potenciar o eliminar algunas de las relaciones que se dan en la competición, con el objetivo de incrementar o mantener el propio rendimiento deportivo. Con ello se pretende, no solo la mejora del rendimiento deportivo del atleta, sino también de su salud trabajando tanto a nivel deportivo como personal. Así pues, se considera fundamental en las etapas de formación, el desempeño de todas las cualidades necesarias para la futura alta competición, y por supuesto, para un desarrollo saludable. Entre todas estas necesidades, aun teniendo muy presentes las físicas, técnicas y tácticas, destacaríamos las psicológicas (Morilla, Pérez, Gamito, Gómez, Sánchez y Valiente, 2003). En este sentido, los trabajos de Godoy-Izquierdo et al. (2007) y López (2009) ponen de manifiesto la necesidad de incluir el entrenamiento psicológico en la preparación deportiva integral de los jugadores de tenis de mesa, dotándoles así de las habilidades psicológicas apropiadas a las exigentes demandas de este deporte. Se ha evidenciado que el entrenamiento psicológico en tenis de mesa es beneficioso a la hora de incrementar los niveles de autoconfianza y el rendimiento deportivo (Marí, 1997). Igualmente, el entrenamiento de estrategias de afrontamiento con tenimesistas se ha mostrado efectivo en la reducción de los niveles de ansiedad precompetitiva (Séve et al., 2007; Urra, 2014).

La mayoría de los autores coinciden en que las técnicas psicológicas que mayor relevancia cobran en el tenis de mesa y en las que se debería poner especial énfasis son: el control de la 
activación (biofeedback, visualización, relajación, entre otras), control de la atención (búsqueda visual o selección de estímulos discriminantes), auto-diálogos internos (por ejemplo, stop-thinking, re-estructuración cognitiva, o auto-feedback), motivación (marcar objetivos deportivos y de realización), control conductual (establecer rutinas entre punto y punto, control visual, entre otros), planificación de la competición (plan pre-partido), técnicas favorecedoras del aprendizaje técnico (como el ensayo mental o aprender por analogías) y táctico (toma de decisiones) y otras referentes a la cohesión de equipo y a la comunicación entre técnicos y jugadores (Godoy-Izquierdo et al., 2007; López, 2009; Marí, 1997; Mingchang, 2014; Reyes, Raimundi y Gómez, 2012; Séve et al., 2007). Además, la exposición crónica al estrés y la recuperación insuficiente puede afectar negativamente en la motivación, el comportamiento y el considerable descenso del rendimiento de los jugadores, e incluso el abandono de la práctica deportiva (Martinent y Decret, 2015).

Por otro lado, el entrenador puede influir positivamente en el desarrollo psicológico de sus deportistas, contribuyendo a fortalecer su motivación y autoconfianza, controlar su estrés, lograr una atención apropiada y una buena cohesión de equipo. Y si además, se trabajan otras estrategias psicológicas más complejas de la mano del psicólogo deportivo, finalmente se conseguirá un incremento positivo en las probabilidades de conseguir el éxito, no solo en rendimiento sino también en su salud (Buceta, 2004). Para trabajar en esta línea, se necesitan propuestas que expliquen métodos de entrenamiento psicológico integrado y orienten sobre el diseño de actividades que permitan incluir las habilidades mentales en la preparación individualizada del deportista (Eraña, 2004; Morilla et al., 2003; Olivares, López y Garcés de Los Fayos, 2016). Partiendo de esta metodología se pueden formar jugadores que, además de ser habilidosos, sean eficientes y resolutivos.

En el presente trabajo se describe una propuesta de entrenamiento psicológico integrado en el tenis de mesa a partir de una experiencia con jugadoras juveniles del equipo nacional internas en el Centro de Alto Rendimiento de Sant Cugat (C.A.R., Barcelona), con el objetivo principal de formar a las deportistas en la adquisición y mejora de las habilidades psicológicas relacionadas con la optimización del rendimiento deportivo. Se hipotetizó, por tanto, que el programa de entrenamiento psicológico aplicado produciría una mejora en las habilidades psicológicas relacionadas con el rendimiento deportivo de las jugadoras de tenis de mesa.

\section{Material y método \\ Descripción del caso}

El programa de entrenamiento que se propone tiene su origen en una experiencia práctica y formativa vivenciada en el C.A.R. de Barcelona por una alumna de cuarto curso del Grado en Ciencias de la Actividad Física y del Deporte, que estuvo supervisada y tutorizada en todo momento por profesionales de Ciencias del Deporte y por un psicólogo deportivo con amplia experiencia profesional en la élite de este deporte. Durante el periodo de intervención se trabajó con dos jugadoras juveniles de la selección española de tenis de mesa, internas en el CAR de Sant Cugat y becadas (gracias a sus logros deportivos) por la Real Federación Española de Tenis de Mesa (RFETM). Las dos jugadoras concilian su vida aca- 
démica y deportiva satisfactoriamente; tienen un rendimiento destacado en su categoría a nivel nacional, compiten a nivel internacional y entrenan diariamente bajo la supervisión de un equipo multidisciplinar formado por médicos, fisiólogos, podólogos, fisioterapeutas, nutricionistas, psicólogos, preparadores físicos y entrenadores que trabajan conjuntamente para optimizar su rendimiento deportivo.

\section{Muestra}

A continuación, se detallan las características sociodemográficas y antropométricas de las dos jugadoras:

Juvenil I: 16 años. Estudiante de primero de Bachillerato. Acumula 10 años de experiencia deportiva. Talla: $1.58 \mathrm{~cm}$. Peso: $50.2 \mathrm{~kg}$.

Juvenil II: 18 años. Estudiante de segundo de Bachillerato. Acumula 12 años de experiencia deportiva. Talla: $1.68 \mathrm{~cm}$. Peso: $60.4 \mathrm{~kg}$.

Se solicitaron las respectivas autorizaciones a la Real Federación Española de Tenis de Mesa (RFETM), al equipo técnico, a las atletas y sus tutores legales (en el caso de la juvenil I) para participar en el estudio.

\section{Variables}

Entrevista semi-estructurada apoyada por un registro ad-hoc para conocer la percepción que las deportistas, su entrenador y su psicólogo deportivo tenían sobre aspectos psicológicos (puntos fuertes y débiles), y poder diseñar el programa de entrenamiento integrado al deportivo en tenis de mesa partiendo de los puntos comunes de los tres puntos de vista (jugadoras-entrenador-psicólogo).

También se realizó el análisis conjunto (deportistas/psicólogo) de las puntuaciones en el Cuestionario de Características Psicológicas relacionadas con el Rendimiento Deportivo (CPRD) de Gimeno, Buceta y Pérez-Llantada (1999), además de las anotaciones específicas en el marco del cuestionario. La estructura factorial de este instrumento está definida por cinco escalas que aglutina un total de 55 ítems: control del estrés, influencia de la evaluación del rendimiento, motivación, habilidad mental y cohesión de equipo. El proceso seguido para la elaboración del cuestionario CPRD y la consistencia interna de conjunto total de ítems (coeficiente alfa de Cronbach $=0,85$ ) permiten considerar este instrumento útil, interactuando con la información procedente de otros procedimientos de evaluación, para ayudar al psicólogo deportivo en la detección de necesidades y recursos, el planteamiento de hipótesis explicativas, la realización de análisis funcionales, la toma de decisión sobre los objetivos de la intervención y la observación del progreso de los deportistas (Gimeno, Buceta yPérez-Llantada, 2001).

\section{Procedimiento}

El programa de entrenamiento psicológico integrado al deportivo en tenis de mesa se implementó a lo largo de la temporada 2014-2015 siguiendo una estructura estandarizada de pre-evaluación, intervención y post-evaluación. Este entrenamiento tenía lugar en el CAR 
Tabla 1.- Valoración subjetiva (jugadora-entrenador-psicólogo) del perfil psicológico de la juvenil I: puntos fuertes y débiles

\begin{tabular}{|c|c|c|c|}
\hline \multicolumn{4}{|c|}{ PERCEPCIÓN DE LA JUGADORA (JUVENIL I) } \\
\hline \multicolumn{2}{|c|}{ Aspectos psicológicos fuertes } & \multicolumn{2}{|c|}{ Aspectos psicológicos débiles } \\
\hline Factor psicológico & Ejemplo & Factor psicológico & Ejemplo \\
\hline \multirow{5}{*}{ No contesta } & Deportivo & \multirow{5}{*}{-Débil mentalmente } & Deportivo \\
\hline & & & $\begin{array}{l}\text { Si voy perdiendo o las cosas no van } \\
\text { bien me desanimo muy rápido. }\end{array}$ \\
\hline & & & \\
\hline & \multirow[t]{2}{*}{ En otro aspecto de mi vida } & & En otro aspecto de mi vida \\
\hline & & & $\begin{array}{l}\text { Me afectan mucho las cosas que me } \\
\text { dicen. }\end{array}$ \\
\hline Factor psicológico & Ejemplo & Factor psicológico & Ejemplo \\
\hline \multirow{4}{*}{ No contesta } & Deportivo & \multirow{4}{*}{$\begin{array}{l}\text {-Demasiado exigente } \\
\text {-Negativa }\end{array}$} & Deportivo \\
\hline & & & $\begin{array}{l}\text { Solo me centro en lo que fallo, hasta } \\
\text { que al final sí que lo acabo fallando } \\
\text { todo. }\end{array}$ \\
\hline & En otro aspecto de mi vida & & En otro aspecto de mi vida \\
\hline & & & $\begin{array}{l}\text { En todo, como en los estudios, que si } \\
\text { no saco un } 9 \text { me siento mal. }\end{array}$ \\
\hline \multicolumn{4}{|c|}{ PERCEPCIÓN DEL ENTRENADOR } \\
\hline \multicolumn{2}{|c|}{ Aspectos psicológicos fuertes } & \multicolumn{2}{|c|}{ Aspectos psicológicos débiles } \\
\hline Factor psicológico & Ejemplo & Factor psicológico & Ejemplo \\
\hline \multirow{4}{*}{$\begin{array}{l}\text {-Orgullo } \\
\text {-Garra } \\
\text {-Inteligencia }\end{array}$} & Deportivo & \multirow{4}{*}{$\begin{array}{l}\text {-Muy negativa } \\
\text {-Desconfiada } \\
\text {-Excesiva frustración } \\
\text {-Poca capacidad de } \\
\text { sufrimiento } \\
\text {-Mala actitud }\end{array}$} & Deportivo \\
\hline & $\begin{array}{l}\text { Muy competitiva. Juega con } \\
\text { mucha intensidad en sus } \\
\text { golpes. }\end{array}$ & & $\begin{array}{l}\text { No acepta el fallo. Le cuesta adaptarse } \\
\text { al cambio y no aprecia su mejoría. } \\
\text { Poca generosidad con sus compañeras } \\
\text { de entrenamiento. }\end{array}$ \\
\hline & En otro aspecto de mi vida & & En otro aspecto de mi vida \\
\hline & $\begin{array}{l}\text { Es una chica muy lista } \\
\text { académicamente, con mucha } \\
\text { capacidad de aprendizaje, } \\
\text { metódica y alegre. }\end{array}$ & & $\begin{array}{l}\text { No la conocemos tanto como para } \\
\text { opinar. }\end{array}$ \\
\hline
\end{tabular}




\begin{tabular}{|c|c|c|c|}
\hline \multicolumn{4}{|c|}{ PERCEPCIÓN DEL PSICOLÓGO DEL DEPORTE } \\
\hline \multicolumn{2}{|c|}{ Aspectos psicológicos fuertes } & \multicolumn{2}{|c|}{ Aspectos psicológicos débiles } \\
\hline Factor psicológico & Ejemplo & Factor psicológico & Ejemplo \\
\hline \multirow{4}{*}{-Ambición } & Deportivo & \multirow{4}{*}{-Flexibilidad } & Deportivo \\
\hline & $\begin{array}{l}\text { Cuando se le pide por sus } \\
\text { objetivos deportivos emplea } \\
\text { un elevado nivel de ambición. }\end{array}$ & & $\begin{array}{l}\text { Valorando un partido es todo o } \\
\text { nada, blanco o negro, no existen las } \\
\text { tonalidades de gris }\end{array}$ \\
\hline & En otro aspecto de mi vida & & En otro aspecto de mi vida \\
\hline & $\begin{array}{l}\text { Nunca se da por satisfecha } \\
\text { con su rendimiento } \\
\text { académico, por elevado que } \\
\text { sea }\end{array}$ & & $\begin{array}{l}\text { Lo mismo ocurre valorando su } \\
\text { rendimiento académico o su } \\
\text { adaptación al centro }\end{array}$ \\
\hline Factor psicológico & Ejemplo & Factor psicológico & Ejemplo \\
\hline \multirow{4}{*}{-Autoexigencia } & Deportivo & \multirow{4}{*}{-Paciencia } & Deportivo \\
\hline & $\begin{array}{l}\text { Se enfada mucho durante los } \\
\text { entrenamientos: a la primera } \\
\text { ocasión en que las cosas no le } \\
\text { salen como ella esperaba. }\end{array}$ & & $\begin{array}{l}\text { Se desespera muy rápido cuando no } \\
\text { es capaz de corregir pronto un gesto } \\
\text { deportivo. }\end{array}$ \\
\hline & En otro aspecto de mi vida & & En otro aspecto de mi vida \\
\hline & Cuida mucho su aspecto físico & & $\begin{array}{l}\text { Se desespera cuando tiene que esperar } \\
\text { por algo o alguien. }\end{array}$ \\
\hline
\end{tabular}

de Sant Cugat (Barcelona) donde las dos jugadoras residían y entrenaban. Las tenimesistas entrenaban con una frecuencia semanal de 5 sesiones de 3 horas de duración (entrenamiento en pista) y se reunían con el psicólogo deportivo una vez al mes para abordar en exclusiva el trabajo psicológico que posteriormente se incluía en las citadas sesiones de entrenamiento en pista. Se trató, por tanto, de una intervención interdisciplinar donde psicólogo del deporte, entrenador y preparador físico colaboraban en la integración del entrenamiento psicológico en la pista resaltando que la instrucción, el seguimiento y el control de las técnicas psicológicas desarrolladas era labor exclusiva del psicólogo deportivo.

\section{Intervención y evaluación}

En este trabajo se desarrolla una propuesta de entrenamiento psicológico integrado en el tenis de mesa en torno a dos niveles de concreción; (a) un primer nivel correspondiente a la planificación anual de la temporada y, (b) un segundo nivel (más específico) donde se ilustra una sesión tipo de entrenamiento. 
Tabla 2.- Valoración subjetiva (jugadora-entrenador-psicólogo) del perfil psicológico de la juvenil II: puntos fuertes y débiles

\begin{tabular}{|c|c|c|c|}
\hline \multicolumn{4}{|c|}{ PERCEPCIÓN DE LA JUGADORA (JUVENIL II) } \\
\hline \multicolumn{2}{|c|}{ Aspectos psicológicos fuertes } & \multicolumn{2}{|c|}{ Aspectos psicológicos débiles } \\
\hline Factor psicológico & Ejemplo & Factor psicológico & Ejemplo \\
\hline \multirow{4}{*}{-Lucha } & Deportivo & \multirow{4}{*}{-Concentración } & Deportivo \\
\hline & $\begin{array}{l}\text { Para demostrar que yo } \\
\text { también quiero lo mejor }\end{array}$ & & $\begin{array}{l}\text { A la mínima que pasa algo } \\
\text { en mi contra pierdo la } \\
\text { concentración. }\end{array}$ \\
\hline & En otro aspecto de mi vida & & En otro aspecto de mi vida \\
\hline & $\begin{array}{l}\text { Para superarme a mí misma } \\
\text { cada día }\end{array}$ & & $\begin{array}{l}\text { En un examen me pongo } \\
\text { nerviosa si no sé la pregunta. }\end{array}$ \\
\hline \multicolumn{4}{|c|}{ PERCEPCIÓN DEL ENTRENADOR } \\
\hline \multicolumn{2}{|c|}{ Aspectos psicológicos fuertes } & \multicolumn{2}{|c|}{ Aspectos psicológicos débiles } \\
\hline Factor psicológico & Ejemplo & Factor psicológico & Ejemplo \\
\hline \multirow{4}{*}{$\begin{array}{l}\text {-Muy perseverante } \\
\text {-Luchadora } \\
\text {-Fuerte mentalmente } \\
\text {-Perceptiva } \\
\text {-Solidaria con sus } \\
\text { compañeros } \\
\text {-Orgullosa }\end{array}$} & Deportivo & \multirow{4}{*}{-Capacidad de análisis } & Deportivo \\
\hline & $\begin{array}{l}\text { No da un punto por perdido } \\
\text { hasta que el árbitro sube el } \\
\text { marcador del rival. }\end{array}$ & & $\begin{array}{l}\text { Le cuesta adaptarse al juego del } \\
\text { rival (gomas antiguas). }\end{array}$ \\
\hline & En otro aspecto de mi vida & & En otro aspecto de mi vida \\
\hline & $\begin{array}{l}\text { Jamás falta a una sesión. } \\
\text { Si no puede venir, avisa y } \\
\text { propone otra fecha. }\end{array}$ & & $\begin{array}{l}\text { Cada vez que debe tomar } \\
\text { decisiones vitales, pide ayuda } \\
\text { para valorar las opciones. }\end{array}$ \\
\hline \multicolumn{4}{|c|}{ PERCEPCIÓN DEL PSICOLÓGO DEL DEPORTE } \\
\hline \multicolumn{2}{|c|}{ Aspectos psicológicos fuertes } & \multicolumn{2}{|c|}{ Aspectos psicológicos débiles } \\
\hline Factor psicológico & Ejemplo & Factor psicológico & Ejemplo \\
\hline \multirow{4}{*}{-Honestidad } & Deportivo & \multirow{4}{*}{-Atrevimiento } & Deportivo \\
\hline & $\begin{array}{l}\text { Cuando ha decidido dejar de } \\
\text { priorizar el tenis de mesa en } \\
\text { su vida lo ha comunicado a } \\
\text { todas las partes implicadas }\end{array}$ & & $\begin{array}{l}\text { Prefiere jugar con guión pre- } \\
\text { establecido que improvisar en } \\
\text { función del momento. }\end{array}$ \\
\hline & En otro aspecto de mi vida & & En otro aspecto de mi vida \\
\hline & $\begin{array}{l}\text { No le he pillado, en años, ni } \\
\text { una sola mentira }\end{array}$ & & $\begin{array}{l}\text { Cuando debe tomar decisiones } \\
\text { personales, le cuesta abandonar } \\
\text { (a pesar de que lo consigue) su } \\
\text { zona de seguridad y confort. }\end{array}$ \\
\hline
\end{tabular}


Para la evaluación, inicialmente se empleó entrevista semi-estructurada apoyada por un registro ad hoc (ver Tabla 1 y Tabla 2) donde se establecieron los puntos psicológicos fuertes y débiles de las dos jugadoras desde tres puntos de vista; las propias jugadoras, su entrenador y el psicólogo del deporte. Algunos ejemplos de las preguntas de la entrevista fueron:

- “A nivel general, y según tu parecer, ¿cuáles consideras como tus/sus aspectos psicológicos fuertes, es decir buenos o muy buenos?"

- “¿Podrías poner algún ejemplo de estos aspectos psicológicos fuertes en tu/su práctica deportiva?"

Tabla 3.- Plan de Competición jugadora juvenil I

\begin{tabular}{|c|c|c|}
\hline Deporte : Tenis de mesa & Fecha: 12-02-2015 & Deportista: Juvenil I \\
\hline Competición: Partidos del entrenamiento $\quad$ Importa & \multicolumn{2}{|c|}{ Importancia de la competición en la temporada (0-10): 6} \\
\hline \multirow{2}{*}{\multicolumn{3}{|c|}{$\begin{array}{l}\text { Indicar la estrategia (táctica) a seguir en el partido ¿Cómo he preparado el partido? } \\
\text { ¿Cómo voy a realizar el partido? ¿Cómo quiero jugar? }\end{array}$}} \\
\hline & & \\
\hline \multicolumn{3}{|c|}{ Debo atacar yo, luchar en todo momento, jugar con cabeza jugándole más por la derecha. } \\
\hline \multicolumn{3}{|c|}{ ¿Qué posibles dificultades puedo encontrarme en el desarrollo de la competición? } \\
\hline \multicolumn{3}{|l|}{ Mi cabeza. } \\
\hline \multicolumn{3}{|l|}{ Que no me entre el revés o el top spin de derecha. } \\
\hline \multicolumn{3}{|c|}{ Para cada una de estas dificultades ¿Qué plan alternativo tengo preparado? } \\
\hline \multicolumn{3}{|l|}{ Luchar. } \\
\hline \multicolumn{3}{|l|}{ Ser positiva y no ver solo lo malo. } \\
\hline \multicolumn{3}{|l|}{ Valoración general del desarrollo de la competición } \\
\hline ¿Se ha presentado alguna dificultad de las previstas? Sí. & ¿Cuál? Que no me entı & tró el revés. \\
\hline \multicolumn{3}{|c|}{ ¿Se ha conseguido solucionar con el plan alternativo? Sí, pero porque la derecha iba más o menos bien. } \\
\hline $\begin{array}{l}\text { ¿Se ha presentado alguna dificultad no } \\
\text { prevista? }\end{array}$ & ¿Se ha conseguido solucionar? & SI \\
\hline \multicolumn{3}{|c|}{ Indicar cómo se ha intentado solucionar y las dificultades encontradas (en su caso) } \\
\hline \multicolumn{3}{|c|}{$\begin{array}{l}\text { Pues me metió muchos puntos y en vez de cabrearme no les di importancia. Y que empecé perdiendo 2-0 porque } \\
\text { estaba "cagada" y no metía una bola y seguí luchando hasta que al final salió. }\end{array}$} \\
\hline \multicolumn{3}{|l|}{ OBSERVACIONES } \\
\hline Mi rival juega muy bien en el intercambio, mete todas las $b$ & las y eso no me da bien. & \\
\hline
\end{tabular}


- “¿Podrías poner algún ejemplo de estos aspectos psicológicos fuertes en cualquier otro aspecto de tu/su vida?"

- "A nivel general, y según tu parecer, ¿cuáles consideras como tus/sus aspectos psicológicos débiles, es decir malos o muy malos?"

Tanto al inicio como al final de la temporada, se llevó a cabo el análisis conjunto (deportistas/psicólogo) de las puntuaciones en el Cuestionario de Características Psicológicas relacionadas con el Rendimiento Deportivo (CPRD) de Gimeno, Buceta y Pérez-Llantada (1999) para comprobar la eficacia de la intervención psicológica desarrollada (ver Figura 1 y Figura 2).

\section{a) Programación anual (primer nivel de concreción)}

En un plano general, partiendo del calendario competitivo de las jugadoras, se programó para una temporada completa, es decir, desde principios de septiembre hasta mediados de julio (10 meses y medio), un plan de trabajo psicológico fraccionado por microciclos o semanas. En dicha programación, se especificaron las fechas de competición regular, tanto de División de Honor como de Súper División, los campeonatos nacionales e internacionales y otros torneos, siendo a mediados de julio el Campeonato de Europa. La carga psicológica que se integra semanalmente a lo largo de la temporada, se dosifica en función de la proximidad de las competiciones y de la relevancia de las mismas.

\section{Contenidos psicológicos trabajados en la programación anual.}

Casi cada semana a lo largo de toda la temporada, se trabajó el "Plan de Competición", para anticipar posibles dificultades que pudieran surgir, favoreciendo la preparación de situaciones que albergaban algún tipo de duda en las jugadoras, aumentando así su autoconfianza y su motivación frente al partido. Además, de una evaluación objetiva y constructiva post-competición, centrada en la revisión de las dificultades encontradas, tanto las previstas como las no previstas, valorando sus recursos y alternativas (ver ejemplo Tabla 3 ).

"Estilo Cognitivo durante la Competición" para indicar qué tipo de pensamientos fluían durante las distintas fases del partido. Mediante esta técnica se pretendía reflexionar acerca de la competición realizada y de los tipos de pensamientos vinculados a cada momento de la misma, con el fin de alertar sobre los pensamientos asociados, por un lado a las dificultades encontradas y por otro a las buenas maniobras realizadas. Esta reflexión y su derivación conductual ayudaron a las jugadoras a planificar estrategias para cada una de las competiciones, incrementando la confianza y la percepción de control. En la Tabla 4 se puede ver un ejemplo.

Con respecto a los "Objetivos de Rendimiento" (o de ejecución), se evaluaban diariamente en el entrenamiento, pues las jugadoras no podían ir a entrenar sin un objetivo en mente que guiara su conducta y les proporcionara percepción de control. Los objetivos se redactaban por escrito, ya que escribir es una conducta organizada y, además, permitía a las jugadoras a comprometerse públicamente con esos propósitos. En este sentido, cualquier profesional del cuerpo técnico que quisiera evaluar cómo estaban trabajando las jugadoras ese día, podía supervisar la hoja de registro de objetivos de rendimiento, y anotar sus apreciaciones 
Tabla 4.- Estilo cognitivo durante la competición jugadora juvenil I

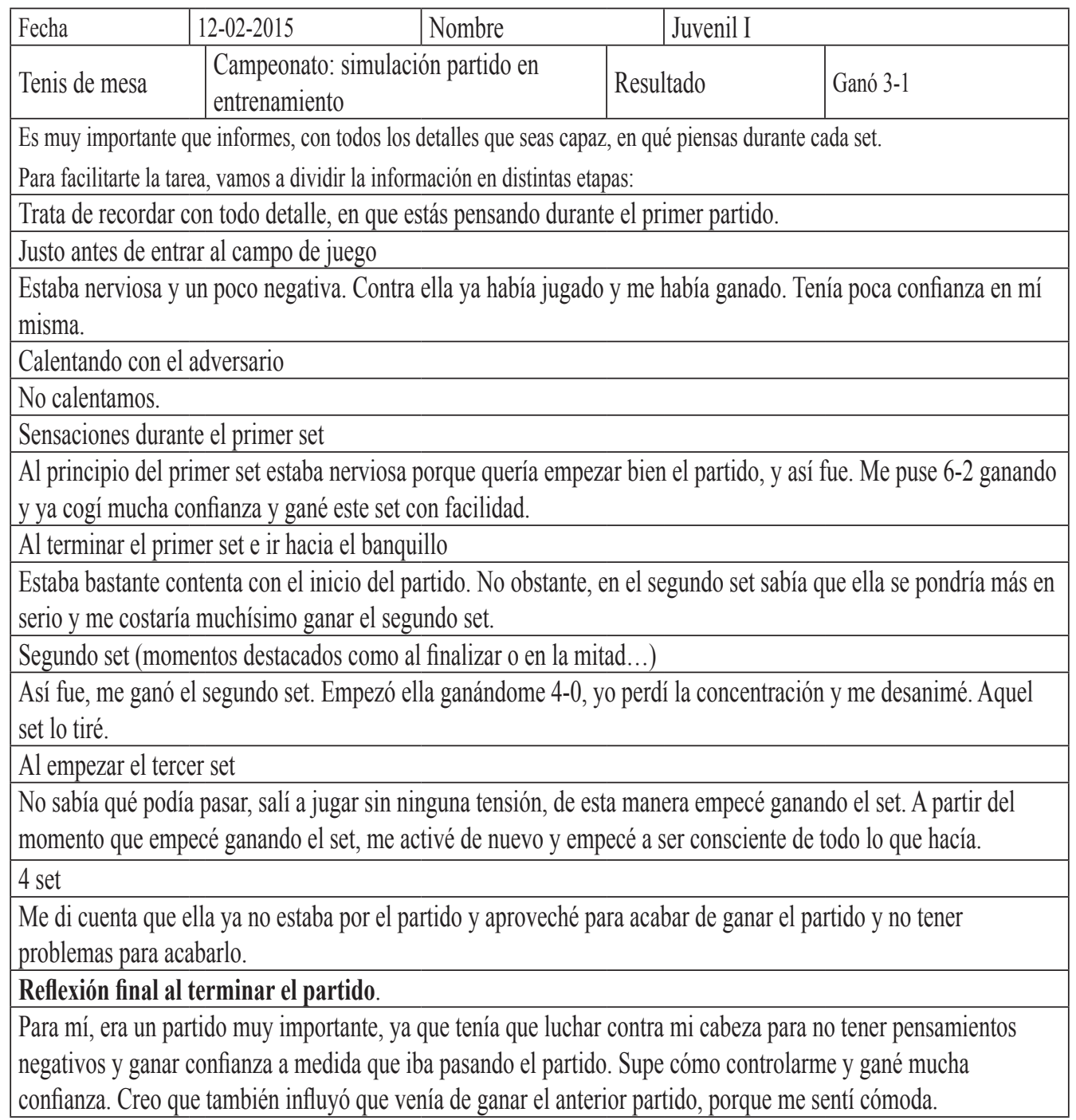

o valoraciones. Por un lado, se focalizaba en algún componente técnico o táctico, y por el otro, trabajaban incidiendo en un aspecto psicológico específico, que podía relacionarse con el objetivo técnico/táctico o diferir por completo. Un ejemplo de objetivo técnico-táctico planteado por una jugadora fue: "asegurar mi top spin de revés para coger más confianza de cara a los partidos"; y la premisa para cumplirlo: "durante todo el entrenamiento trataré de dar más efecto a la pelota cuando ejecute el top spin de revés para fallar lo mínimo posible. En los ejercicios que se combinen el spin de revés y de derecha focalizaré mi atención en el spin de revés y me permitiré arriesgar un poco más con la derecha". Esta misma jugadora se planteó para la misma sesión de entrenamiento como objetivo psicológico, "mante- 
ner la concentración todo el entrenamiento y no perder de vista en ningún ejercicio mi foco de atención (la pelota)"; y como premisa para cumplirlo, "botar una vez la pelota antes de sacar e iniciar el punto".

"Objetivos para la Competición" (o de resultado). A través de esta técnica se pretendía incrementar la concentración en los aspectos claves a conseguir para cada una de las competiciones. En un primer momento las deportistas antes de la competición indicaban los dos objetivos clave a conseguir. Una vez terminada la competición y después de haber descansado evaluaban el grado de consecución de los objetivos propuestos, indicando los aspectos que a su parecer habían facilitado o dificultado la consecución de los objetivos.

En numerosas situaciones de partido las jugadoras parecían no mantener su pensamiento dentro de las líneas racionales, lógicas y reales, cayendo en exageraciones, distorsiones, equívocos, malas interpretaciones y mostraban una actitud muy negativa. Por ello, se les instruyó durante todo el año en la técnica psicológica de la "Reestructuración cognitiva + Auto-instrucciones". Con ello, se pretendía modificar el lenguaje de las jugadoras para analizar la realidad, y cambiar sus pensamientos negativos por otros positivos o más realistas. Para poner en marcha esta estrategia, las jugadoras se apoyaron un "Diario de éxitos" propio. En él escribían todos los éxitos conseguidos en cada entrenamiento (útil para analizar las causas y factores de los que dependen estos éxitos), una frase al día de confianza que debían repetirse en los entrenamientos, y un repertorio de palabras auto-motivadoras para apoyarse durante los entrenamientos o competiciones, deshacerse de los pensamientos negativos e irracionales y ayudar al control de la activación. Con respecto a la Visualización, se trabajó combinada con ejercicios de Relajación y Respiración, siempre bajo la dirección del psicólogo deportivo y partiendo de una visión muy general de esta estrategia, hasta llegar (a mediados/finales de temporada) al trabajo más específico y próximo a los aspectos deportivos. Las tenimesistas no tenían experiencia previa con la práctica imaginada, por lo que se empezó con imágenes cotidianas (tales como visualizar colores, objetos, paisajes, olores,...) llegando a los gestos deportivos propios del tenis de mesa e incluso a determinadas jugadas tácticas.

b) Diseño y descripción del entrenamiento psicológico integrado al deportivo en tenis de mesa: sesión tipo de entrenamiento psicológico integrado en tenis de mesa (segundo nivel de concreción)

En el segundo nivel de concreción, se presenta una "sesión tipo de entrenamiento" como un ejemplo de integración del componente psicológico al trabajo en la mesa. La sesión tipo de entrenamiento que se expone en la Tabla 5 se compone de una parte inicial, dedicada al calentamiento; la parte central o principal donde la sesión toma una mayor intensidad, y una parte final o vuelta a la calma, en la que predominan ejercicios de saque, relajación, respiración y visualización. Todos los ejercicios están diseñados desde la perspectiva de dos jugadoras diestras.

\section{Seguimiento de la intervención}

El seguimiento y control de la aplicación de cada uno de los contenidos del programa de intervención psicológica y la evaluación de las competiciones se realizó mediante la revisión 
Tabla 5.- Sesión tipo de entrenamiento psicológico integrado en tenis de mesa

\begin{tabular}{|c|c|c|c|c|}
\hline \multicolumn{5}{|c|}{$\begin{array}{c}\text { " INTEGRACIÓN DE CONTENIDOS PSICOLÓGICOS EN UNA SESIÓN DE ENTRENAMIENTO EN } \\
\text { TENIS DE MESA " }\end{array}$} \\
\hline \multicolumn{5}{|c|}{ 1. Planificación y organización } \\
\hline \multicolumn{5}{|c|}{ 1.1 Objetivos de la sesión práctica: responder a tres preguntas clásicas en el entrenador de tenis de mesa. } \\
\hline \multicolumn{5}{|c|}{$\begin{array}{l}\left.1^{\mathrm{a}}\right) \text { ¿Cómo incluir aspectos psicológicos en la mejora de las habilidades o capacidades de la jugadora? } \\
\left.2^{\mathrm{a}}\right) \text { ¿De dónde se pueden obtener ejercicios variados para la mejora de sus capacidades y/o habilidades? } \\
\left.3^{\mathrm{a}}\right) \text { ¿Qué aspectos psicológicos se pueden trabajar en la mesa? }\end{array}$} \\
\hline \multicolumn{5}{|c|}{ 1.2 Contenidos que se contemplan } \\
\hline $\begin{array}{l}\text { Técnicos: } \\
\text { - Top spin de revés } \\
\text { - Top spin de derecha } \\
\text { - Contratopspin de revés } \\
\text { - Contratopspin de derecha } \\
\text { - Fly de revés } \\
\text { - Fly de derecha } \\
\text { - Corte de revés } \\
\text { - Corte de derecha } \\
\text { - Bloqueos activos y pasivos de } \\
\text { revés } \\
\text { - Bloqueos activos y pasivos de }\end{array}$ & $\begin{array}{l}\text { Tácticos: } \\
\\
\text { - Principios ofensivos } \\
\text { - Principios defensivos }\end{array}$ & \multicolumn{2}{|c|}{$\begin{array}{l}\text { Psicológicos: } \\
\text { - Control de la concentración y atención } \\
\text { - Control de la activación } \\
\text { - Motivación con objetivos } \\
\text { - Autoconfianza } \\
\text { - Control emocional } \\
\text { - Percepción y toma de decisión } \\
\text { - Comunicación con la compañera y el entrenador } \\
\text { - Trabajo en equipo y cohesión grupal }\end{array}$} & $\begin{array}{l}\text { Físicos: } \\
\text { - Velocidad } \\
\text { - Resistencia } \\
\text { - Agilidad } \\
\text { - Precisión } \\
\text { - Velocidad de } \\
\text { reacción } \\
\text { - Coordinación } \\
\text { - Potencia }\end{array}$ \\
\hline \multicolumn{5}{|c|}{ 1.3 Metodología } \\
\hline $\begin{array}{l}\text { 1.3.1. Principios básicos: } \\
\text { - Enfoque integrado } \\
\text { - Implicación cognitiva } \\
\text { - Conocimiento de resultado } \\
\text { - Aprendizaje significativo } \\
\text { - Las actividades (dificultad } \\
\text { jugador/a. }\end{array}$ & nporal y perceptiva, & tensidad se deben adap & desarrollo evolt & apetitivo del \\
\hline \multicolumn{5}{|c|}{ 1.4. Recursos y evaluación } \\
\hline $\begin{array}{l}\text { A.) Recursos humanos: } \\
\text { - Entrenador } \\
\text { - Psicolólogo o evaluador } \\
\text { - Jugadoras }\end{array}$ & $\begin{array}{l}\text { B.) Recur } \\
\text { - Mesas } \\
\text { - Pelotas } \\
\text { - Botellas } \\
\text { - Pañuelos } \\
\text { - Gomas C }\end{array}$ & $\begin{array}{l}\text { les: } \\
\text { tas } \\
\text { vacias } \\
\text { para dividir el campo } \\
\text { efectos }\end{array}$ & $\begin{array}{l}\text { C.) Evaluación: } \\
\text { - Cuerpo técnico } \\
\text { - Jugadores/as: }\end{array}$ & ntarios en grupo \\
\hline
\end{tabular}

periódica de los autorregistros utilizados por las jugadoras y de los resultados deportivos alcanzados.

\section{Tipo de diseño}

Se utilizó un diseño de estudio de caso único pre-post intervención, comprobándose de forma intraindividual los objetivos e hipótesis propuestos mediante un enfoque descriptivo y explicativo; por ello la validez y controlabilidad son limitadas.

\section{Resultados}

La evaluación final de la intervención se realizó a través de entrevistas individuales con el cuerpo técnico, observación de los resultados y conductas deportivas en competición. Con las deportistas se realizó un análisis conjunto (deportista/psicólogo) de las puntuaciones obtenidas en el CPRD (que se cumplimentó de nuevo) y su comparación con las obtenidas 


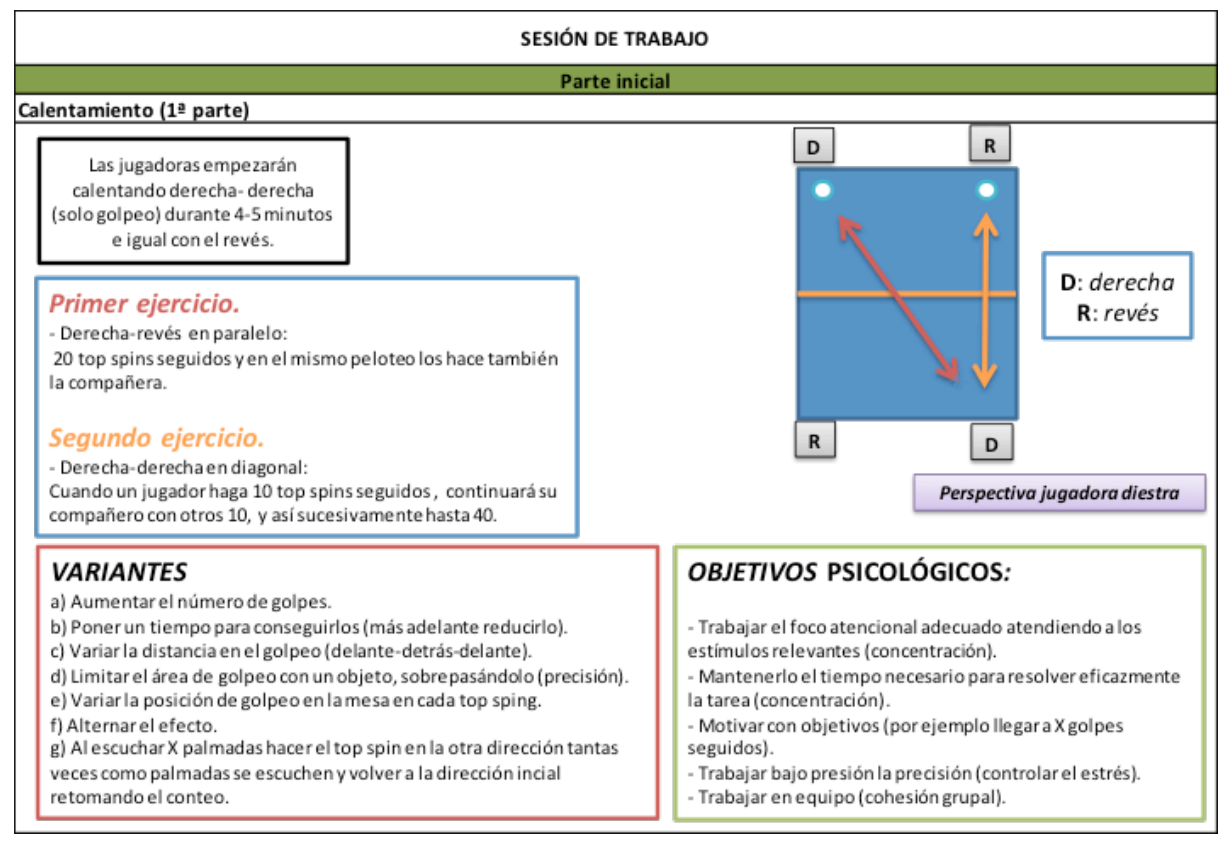

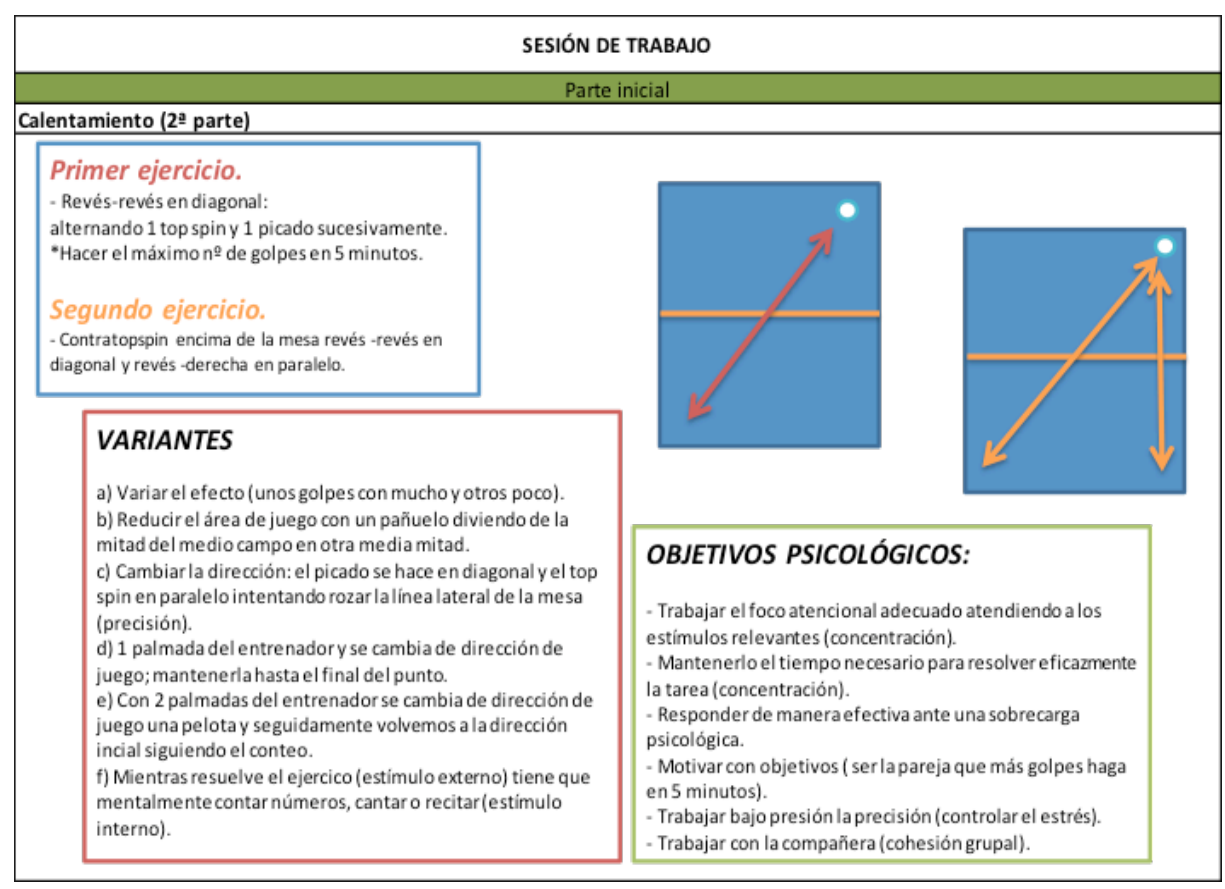




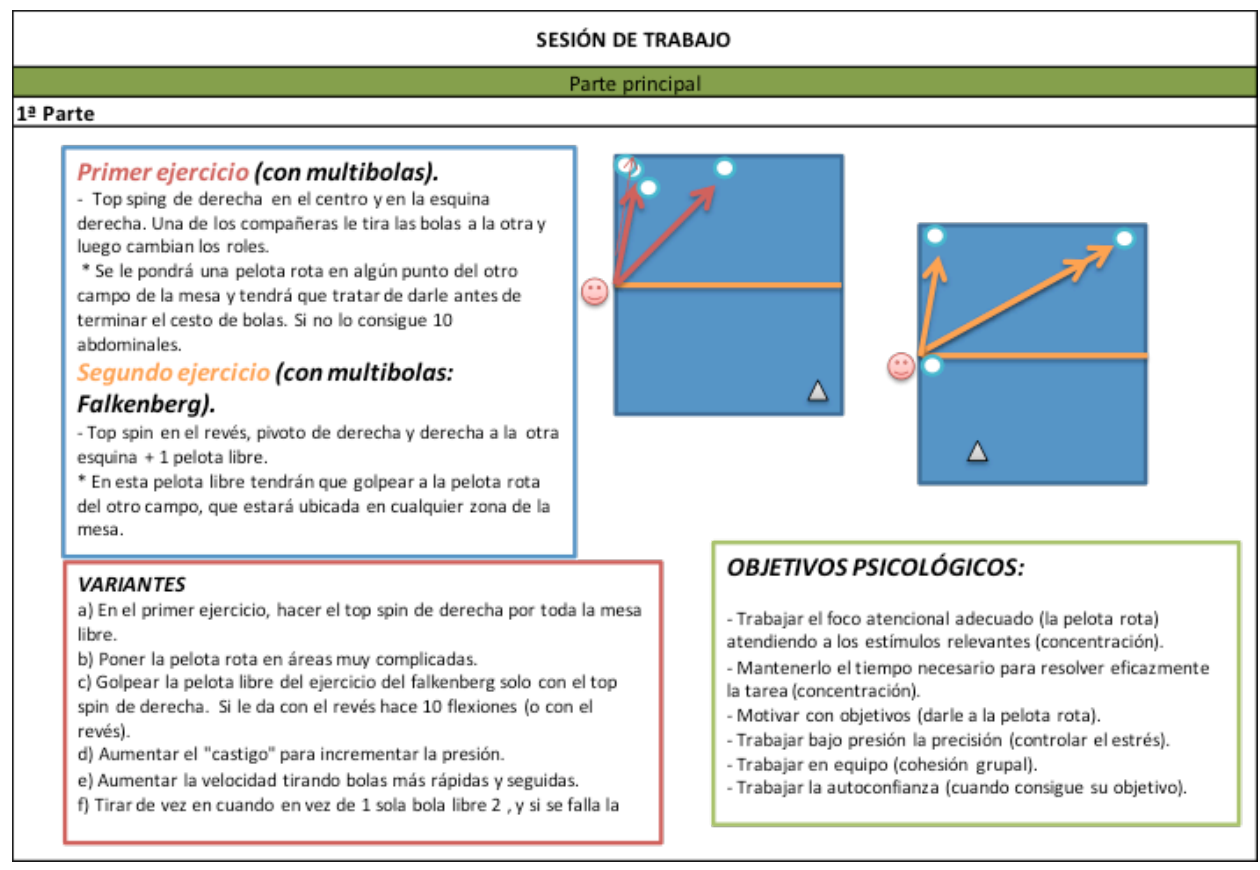

\begin{tabular}{|c|c|c|}
\hline \multicolumn{3}{|c|}{ SESIÓN DE TRABAJO } \\
\hline \multicolumn{3}{|c|}{ Parte principal } \\
\hline \multicolumn{3}{|l|}{ 2a Parte } \\
\hline $\begin{array}{l}\text { Primer ejercicio (con multibolas). } \\
\text { - Primera bola hace top spin de revés en el revés, } \\
\text { segunday tercera van libres portoda la mesa. } \\
\text { En estos tres golpes tendrá que elegir la pelota que mejor } \\
\text { le venga para intentar derribar un botella vacia ubicadaen } \\
\text { cualquier parte del otro campo de la mesa. } \\
\text { " Si no lo consigue en todo el cesto hará } 1 \text { más. } \\
\text { Segundo ejercicio (con multibolas). } \\
\text { - Pelotas libres por toda la mesa a alta velocidad. } \\
\text { "La otra compañera dirá de vez en cuando " } 3,2,1 " \text { (con } \\
\text { cada número tirará una pelota) y en el "1" la jugadora } \\
\text { intentará derribar la botella vacía del otro campo. }\end{array}$ & 00 & 000 \\
\hline $\begin{array}{l}\text { VARIANTES } \\
\text { a) En el primer ejercicio, hacer primero otro gesto técnico cc } \\
\text { b) Hacer las tres bolas libres, parar } 1 \text { segundo y asi sucesivar } \\
\text { c) Variar la velocidad al tirar las pelotas (aumentarla para di } \\
\text { reducirla para dar ventaja). } \\
\text { d) Cambiar el efecto en cada pelota (unas cortadas otras lisa } \\
\text { spin...). } \\
\text { e) Hacer una serie de } 3 \text { en las que el jugador tiene que golpe } \\
\text { distancia de la mesa y la otra serie cerca, e ir alternando suc } \\
\text { f) Poner más botellas a derribar. } \\
\text { g) La jugadora que lanza las bolas tendrá una pala con una g } \\
\text { otra lisa, e irá golpeando con ambas caras de la pala. }\end{array}$ & $\begin{array}{l}\text { elfly. } \\
\text { te. } \\
\text { taro } \\
\text { tras con } \\
\text { mayor } \\
\text { amente. } \\
\text { de picosy }\end{array}$ & $\begin{array}{l}\text { OBJETIVOS PSICOLÓGICOS: } \\
\text { - Trabajar el foco atencional adecuado (la botellavacía) } \\
\text { atendiendo a los estímulos relevantes (concentración). } \\
\text { - Mantenerlo el tiempo necesario para resolver } \\
\text { eficazmente la tarea (concentración). } \\
\text { - Motivar con objetivos (derribar la botella). } \\
\text { - Trabajar bajo presión la precisión (controlar el estrés). } \\
\text { - Trabajar en equipo (cohesión grupal). } \\
\text { - Potenciar la autoconfianza (cuando consigue su objetivo } \\
\text { incrementa). } \\
\text { - Desarrollar la percepción y toma de decisión (seleccionar }\end{array}$ \\
\hline
\end{tabular}




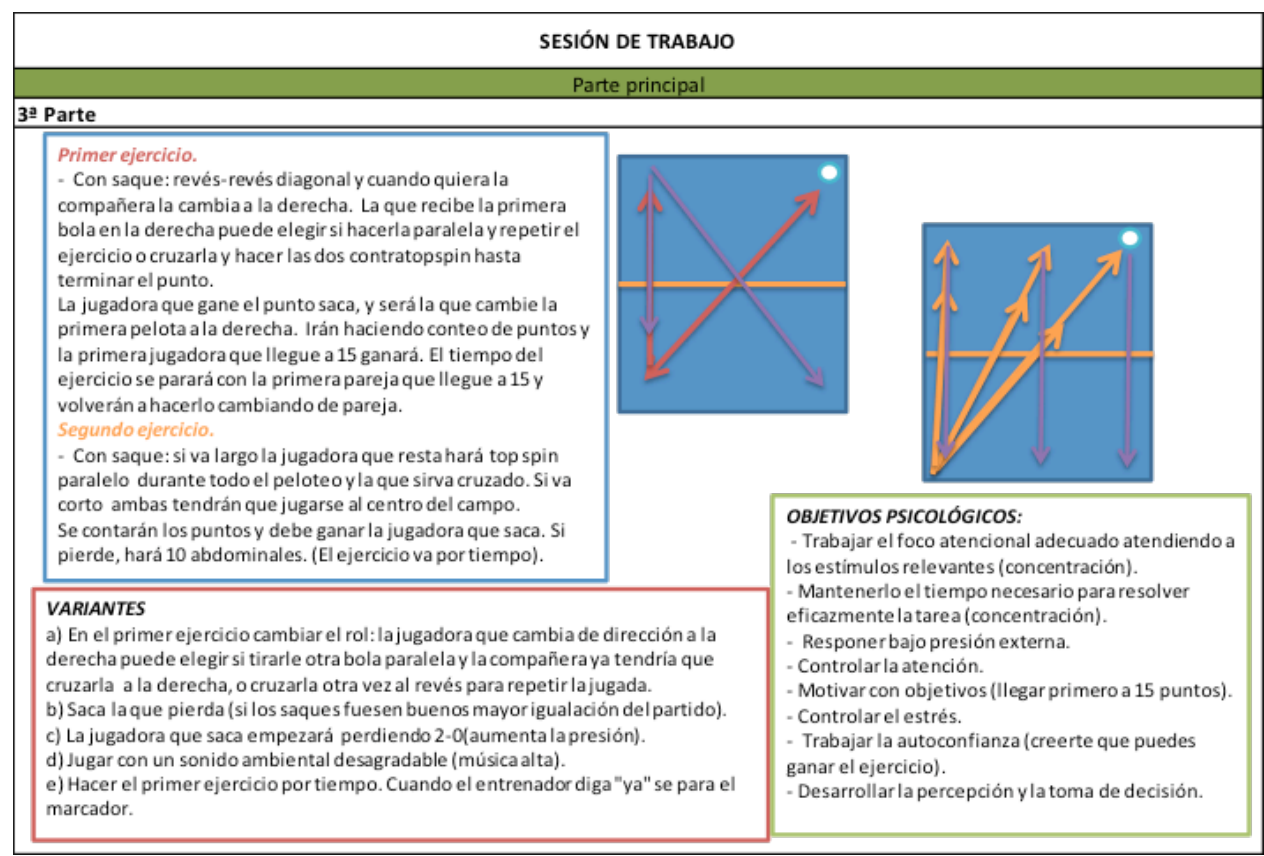

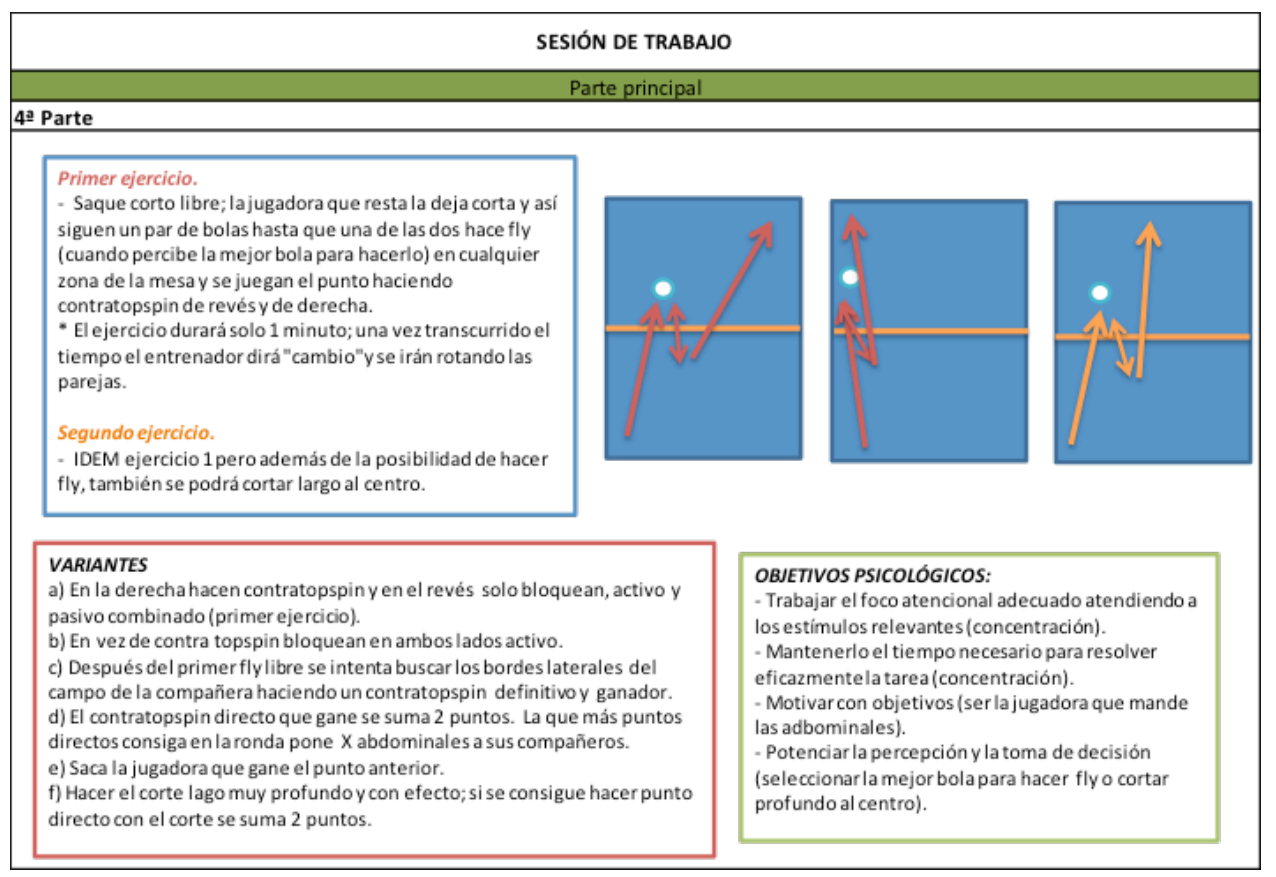




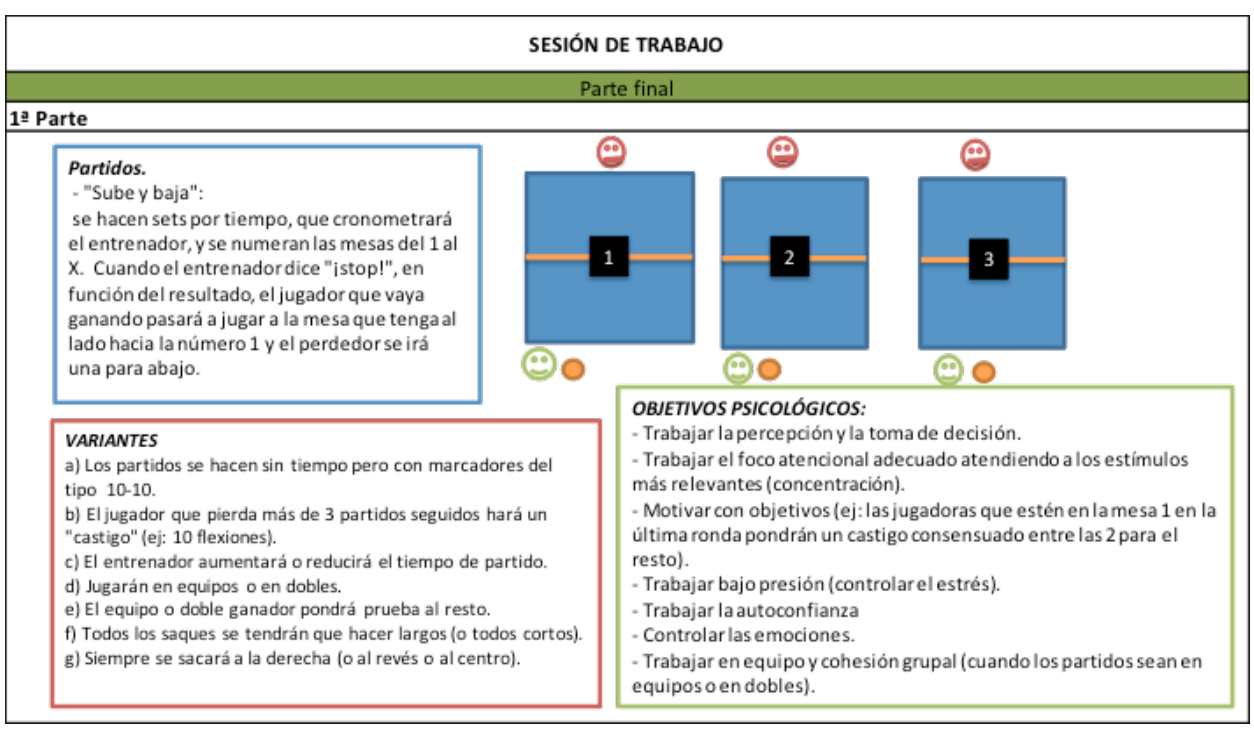

\begin{tabular}{|c|c|}
\hline \multicolumn{2}{|l|}{ SESIÓN DE TRABAJO } \\
\hline \multicolumn{2}{|l|}{ Parte final } \\
\hline 23 Parte & \\
\hline $\begin{array}{l}\text { VARIANTES } \\
\text { a) Se hacen equipos. Si alguno de los miembros del equipo no hace sus } 7 \\
\text { saques dentro del campo, todo su grupo hará } 10 \text { minutos más de saques. } \\
\text { b) Aumentar el número de aciertos en } 10 \text { saques (ej: } 8 \text { de } 10 \text { ). } \\
\text { c) Hacerlos con el entrenador mirando justo enfrente del campo contrario. } \\
\text { d) Individualizar el "castigo" si se fallan más de } 3 \text { saques (ej: si fallan } 4 \\
\text { saques hacen } 11 \text { minutos extra; si fallan } 5 \text { hacen } 12^{\prime} . \text {.) } \\
\text { e) Las jugadoras espectadoras podrán distraer a la jugadora con ruidosy } \\
\text { gritos mientras hace sus saques en el examen final. } \\
\text { f) La jugadora que más bolas rotas toque en los } 10 \text { minutos libres de saque, } \\
\text { se evitará el posible "castigo" si falla más de } 3 \text { saques. } \\
\text { g) El examen será teniendo que golpear de } 10 \text { saques mínimo } 1 \text { veza la } \\
\text { pelota rota que haya en el otro campo (si no se consigue, } 5 \text { minutos más de } \\
\text { saque). } \\
\text { h) Si golpea más de tres veces la pelota rota con sus saques, no hace más } \\
\text { examenes finales (de saque) en esa semana. }\end{array}$ & $\begin{array}{l}\text { IPuedo hacerlo! } \\
\text { Son solo } 7 \text { de } 10\end{array}$ \\
\hline
\end{tabular}




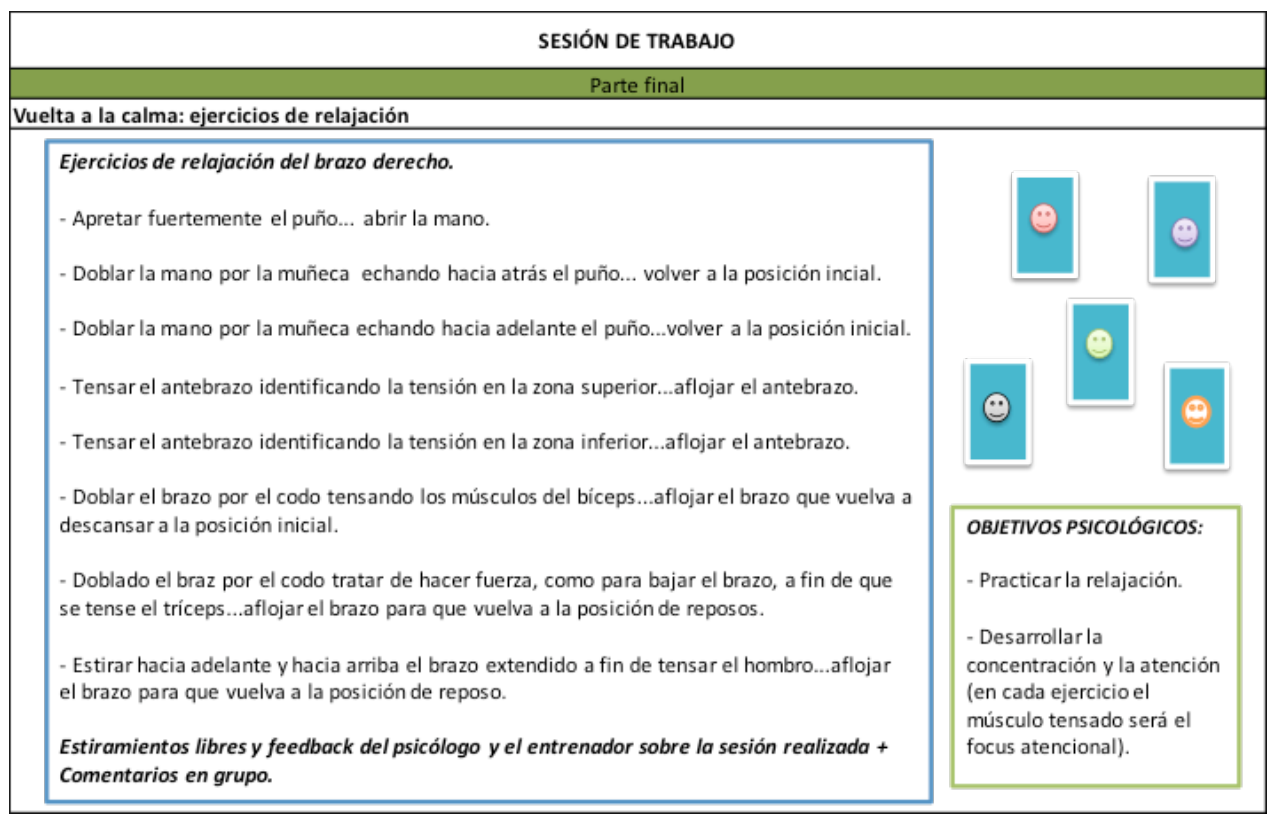

al inicio de la intervención (ver Figura 1 y Figura 2). A través de los resultados obtenidos en el CPRD inicial y final, podemos observar las diferencias en el perfil psicodeportivo de las dos jugadoras de tenis de mesa analizadas. En la Figura 1 (Juvenil I) y Figura 2 (Juvenil II) podemos ver las puntaciones iniciales y finales de las cinco escalas del CPRD; Control de Estrés (CE), Influencia de la Evaluación del Rendimiento (IER), Motivación (M), Habilidad Mental (HM) y Cohesión de Equipo $(\mathrm{CH})$ para cada una de las jugadoras con las que se intervino durante la temporada.

En el caso de la jugadora juvenil I, los cambios presentados en las puntuaciones centiles pre-post de las subescalas del CPRD son: en Control del Estrés se produce un leve aumento (3-10); también se progresa favorablemente en Influencia de la Evaluación del Rendimiento (25-40) así como en Motivación (25-45); sin embargo, se produce un ligero descenso en Habilidad Mental (70-55) y un mantenimiento en la Cohesión de Equipo (75).

Los resultados iniciales y finales del CPRD de la tenimesista juvenil II revelan un incremento importante en las puntuaciones centiles de las subescalas Control del Estrés (12.5-26), Influencia de la Evaluación del Rendimiento (35-82.5) y Habilidad Mental (20-35), y un descenso en Motivación (30-13) y en Cohesión de Equipo (65-45).

\section{Discusión y conclusiones}

Los resultados de la intervención psicológica desarrollada con las tenimesistas han cumplido con el objetivo principal evidenciando, en términos generales, una mejora en el dominio de las habilidades psicológicas relacionadas con la optimización del rendimiento deportivo. 


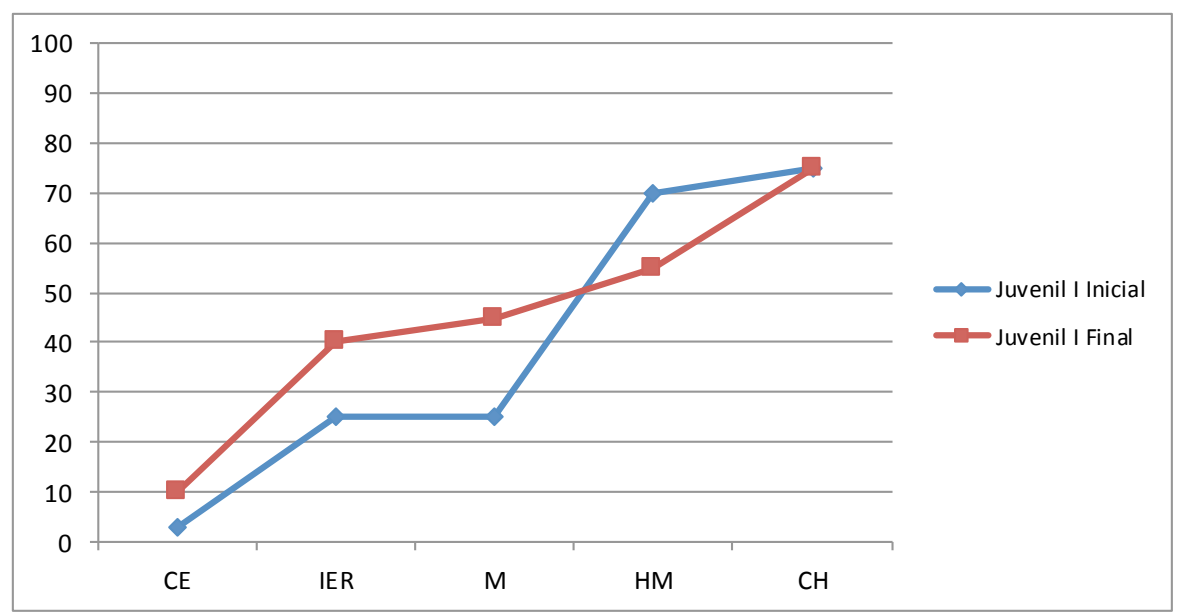

Figura 1.- Diferencias en el perfil psicodeportivo inicial y final de la jugadora Juvenil I de tenis de mesa.

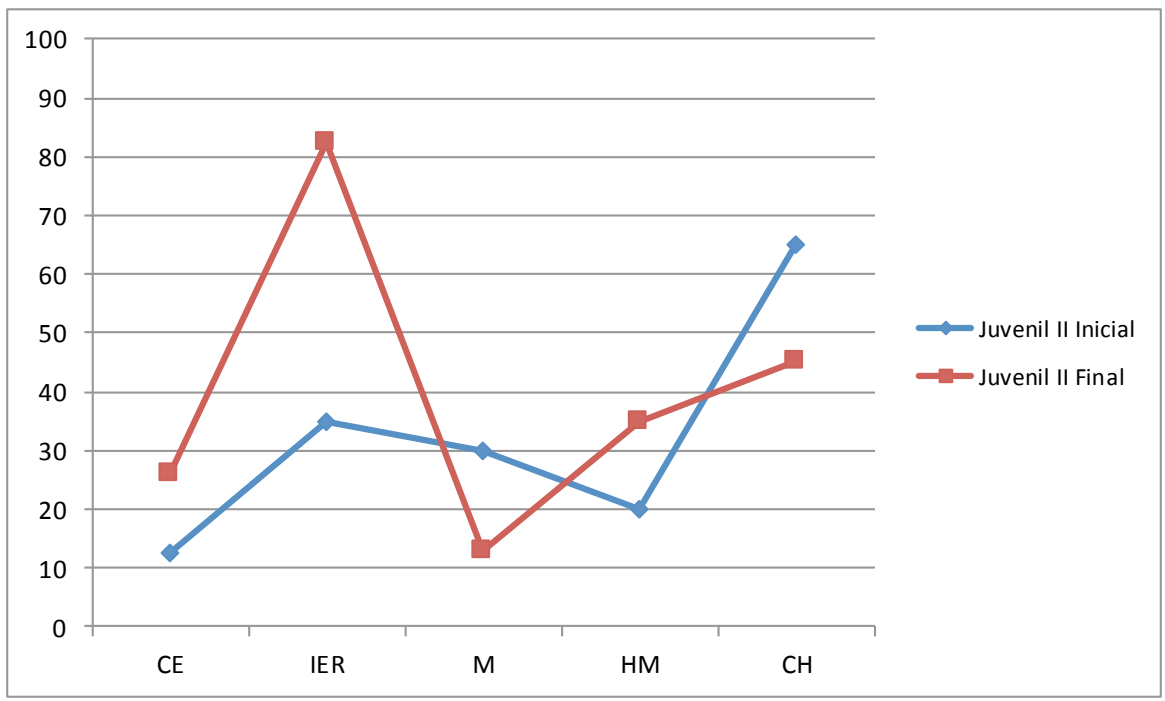

Figura 2.- Diferencias en el perfil psicodeportivo inicial y final de la jugadora Juvenil II de tenis de mesa.

Las bajas puntuaciones en los perfiles iniciales de las dos jugadoras en escalas como Control de Estrés (3 y 12.5), Influencia de la Evaluación del Rendimiento (25 y 35) y, en el caso de la juvenil II también Habilidad Mental (20), indicaron que estas deportistas no controlaban adecuadamente el estrés potencial de la competición, estaban afectadas por la evaluación (propia y ajena) de su rendimiento deportivo, afectando negativamente a la autoconfianza y al control de la activación y además, en el caso de la juvenil II, a un nulo empleo de recursos 
y habilidades psicológicas. Junto a ello, su nivel motivacional no parecía el más adecuado (25 y 30) para atender a las exigentes demandas del alto rendimiento deportivo.

Las percepciones subjetivas sobre las fortalezas y debilidades psicológicas manifestadas inicialmente por el trinomio jugadora-entrenador-psicólogo deportivo dieron lugar a reveladoras coincidencias. Así, en el caso de la juvenil I sorprendió que la negatividad y su consecuencia comportamental en la mesa reflejada en su "mala actitud" (según su entrenador) y poca paciencia (según su psicólogo deportivo), sumado a la ausencia de fortalezas psicológicas (según la jugadora) respaldaran el déficit de recursos psicológicos para el Control del estrés y la Influencia de la Evaluación del Rendimiento revelado en los resultados del CPRD. En esta misma línea, con la juvenil II el acuerdo en cuanto a los puntos débiles (control de la atención y autoconfianza) y los puntos fuertes (lucha, perseverancia y compromiso) de la jugadora coincidió con los bajos valores obtenidos en el CPRD (escalas de Control de estrés y de Influencia de la Evaluación del Rendimiento).

En ambos casos (juvenil I y juvenil II), el aumento en las puntuaciones obtenidas en el CPRD para la mayoría de las cinco escalas que mide este instrumento, determina un perfil psicodeportivo final mejorado respecto al inicial que refleja la eficacia en el programa de intervención psicológica. Concretamente, estos resultados concuerdan con numerosos trabajos que destacan la importancia de la intervención psicológica en deportistas dotándoles de recursos psicológicos útiles para contrarrestar los altos niveles de ansiedad y estrés asociados a los exigentes requerimientos de la competición (López, 2009; Olivares et al., 2016; Olmedilla, Ortega, Andreu, y Ortín, 2010; Séve et al., 2007; Urra 2014).

Cabe destacar como aspecto relevante también, el ligero descenso en la escala de Habilidad Mental mostrada por la juvenil I al finalizar la intervención explicado por el momento de la cumplimentación del CPRD final, justo después de su desafortunada participación en un torneo clasificatorio nacional donde tuvo un rendimiento deportivo pobre, muy alejado de las expectativas y objetivos planteados para esa competición. Hay que recordar que esta jugadora no reconoce tener ninguna fortaleza psicológica en la evaluación inicial y que, sin embargo, coincide con su entrenador y psicólogo en que es "negativa" a la hora de valorarse y afrontar la competición. En casos como este donde se evidencia un afrontamiento ineficaz de situaciones competitivas problemáticas parece apropiado tomar como referencia trabajos que describen intervenciones psicológicas específicas con atletas en situaciones de crisis (Abenza, Bravo y Olmedilla, 2006; Latinjak, Font-Lladó, Zourbanos Hatzigeorgiadis, 2016; Nieto y Olmedilla, 2001). Igualmente, el descenso en el nivel de la escala Motivación de la juvenil II se explica por su decisión de abandonar la práctica del tenis de mesa a un nivel de rendimiento al finalizar la temporada para centrarse en la carrera universitaria que iniciaba el siguiente curso académico. El descenso del nivel motivacional de los tenimesistas jóvenes que están internos en centros de alto rendimiento a lo largo de la temporada es un hecho estudiado por Martinet y Decret (2015), que lo relacionan con la confluencia temporal del final de curso académico (exámenes finales, más tarea) con el fin de la temporada competitiva (partidos muy importantes, periodos de entrenamiento más largos, más presión). 
Por otra parte, en respuesta al llamamiento derivado de los resultados de la revisión bibliográfica (1997-2012) de Barker, Mellalieu, McCarthy, Jones y Moran (2013) evidenciando la predominante presencia de estudios de caso único sobre intervenciones psicológicas con atletas no profesionales, este trabajo describe la experiencia profesional con tenimesistas profesionales y de nivel internacional. Finalmente, tiene el valor añadido de ilustrar sobre la integración del trabajo psicológico al deportivo realizado en el terreno de juego ampliando la línea de lo expuesto en estudios donde se describen programas de formación que combinan diferentes técnicas psicológicas para la mejora del rendimiento deportivo (Barker et al., 2013).

\section{Referencias}

Abenza, L., Bravo, J.F. y Olmedilla, A. (2006). Estrategias psicológicas para una intervención en crisis: un caso en balonmano femenino. Revista de Psicología del Deporte, 15(1), 109-125.

Barker, J.B., Mellalieu, S.D., McCarthy, P.J. Jones, M.V. y Moran, A. (2013). A Review of Single-Case Research in Sport Psychology 1997-2012: Research Trends and Future Directions. Journal of Applied Sport Psychology, 25, 4-32.

Buceta, J.M. (2004) Estrategias psicológicas para entrenadores de deportistas jóvenes. Madrid: Dykinson.

Eraña, I. (2004). Entrenamiento psicológico con jóvenes tenistas. Revista de Psicología del Deporte, 13(2), 263271.

Duan, W. (2014). Exploration of the importance and application of the training of the psychological factors in the table tennis teaching. Advances in Education Research, 55, 175-179.

Gimeno, F., Buceta, J.M. y Pérez-Llantada, M.C. (1999). El cuestionario de «Características psicológicas relacionadas con el Rendimiento Deportivo» (C.P.R.D.): Características psicométricas. En A. López de la Llave, M.C. PérezLlantada y J.M. Buceta (eds.): Investigaciones breves en Psicología del Deporte (pp. 65-76). Madrid: Dykinson.

Gimeno, F., Buceta, J.M. y Pérez-Llantada, M.C. (2001). El cuestionario «Características Psicológicas Relacionadas con el Rendimiento Deportivo» (CPRD): Características psicométricas. Análise Psicológica, 1 (XIX): 93-113.

Godoy-Izquierdo, D., Vélez, M. y Pradas, F. (2007). Nivel de dominio de las habilidades psicológicas en jóvenes jugadores de tenis de mesa, bádminton y fútbol. Revista de Psicología del Deporte, 18(1), 7-22.

Latinjak, A.T., Font-Lladó, R., Zourbanos, N. y Hatzigeorgiadis, A. (2016). Goal-Directed Self-Talk Interventions:A Single-Case Study With an Elite Athlete. The Sport Psychologist, 30, 189-194.

López, J.C. (2009). Habilidades psicológicas para la mejora del rendimiento en tenis de mesa. Cuadernos de Psicología del Deporte, 9(1), 53-72.

Marí, J. (1997). Programa de entrenamiento psicológico para jugadores de tenis de mesa de alto nivel. Revista de Psicología del Deporte, 6(2), 77-90.

Martinent, G. y Decret, J.C. (2015). Motivational Profiles Among Young Table-Tennis Players in Intensive Training Settings: A Latent Profile Transition Analysis. Journal of Applied Sport Psychology, 27, 268-287.

Mingchang, L. (2014). Analysis on the importance of Psychological factors in the selection of juvenile table tennis talents. Psychology Research, 15, 191-195.

Mora, J.A., Zarco, J.A. y Blanca, M.J. (2001). Atención-concentración como entrenamiento para la mejora del rendimiento deportivo en jugadores profesionales de fútbol. Revista de Psicología del Deporte, 10(1), 49-65.

Morilla, M., Pérez, E., Gamito, J.M., Gómez, M.Á., Sánchez, J.E. y Valiente, M. (2003). Planificación psicológica de la cantera del Sevilla F.C. S.A.D.: organización, funcionamiento y programa deportivo-formativo. Cuadernos de Psicología del Deporte, 3(2), 18-30. 
Nieto, G. y Olmedilla, A. (2001). Planificación del entrenamiento psicológico en atletas de élite: un caso en marcha Atlética. Revista de Psicología del Deporte, 10(1), 127-142.

Olivares, E. M., López. J.J. y Garcés de Los Fayos, E.J. (2016). Entrenamiento psicológico en tiro olímpico: estudio e un caso. Revista de Psicología del deporte, 25(1), 131-135.

Olmedilla, A., Ortega, E., Andreau, M.D. y Ortín, F.J. (2010). Programa de intervención psicológica en futbolistas: evaluación de habilidades psicológicas mediante el CPRD. Revista de Psicología del Deporte, 19(2), 249-262.

Reyes, M., Raimundi, M.J. y Gómez, L. (2012). Programa de entrenamiento en habilidades psicológicas en jugadoras de voleibol de alto rendimiento. Cuadernos de Psicología del Deporte, 12(1), 9-16.

Séve, C., Ria, L., Poizat, G., Saury, J. y Durand, M. (2007). Performance-induced emotions experienced during highstakes table tennis matches. Psychology of Sport and Exercise, 8, 25-46.

Urra, B. (2014). Evaluación de la efectividad del entrenamiento de estrategias de afrontamiento en el nivel de ansiedad precompetitiva en tenimesistas. Revista de Psicología del Deporte, 23(1), 67-74. 